\title{
Dietas populares: Alimentos crudos ${ }^{1}$
}

\author{
Alexa Barad, Daniela Rivero-Mendoza, y Wendy J Dahl²
}

La dieta de alimentos crudos tiene sus raíces en un movimiento vegetariano que se remonta a los años 1800 (Leitzmann 2014). Como su nombre lo indica, una dieta de alimentos crudos es un patrón dietético compuesto mayoritaria o completamente por alimentos crudos y sin procesar. Esta publicación explora los posibles beneficios y riesgos para la salud de una dieta de alimentos crudos.

\section{¿Qué es una dieta de alimentos crudos?}

Una dieta de alimentos estrictamente crudos se define como aquella en la que el $90 \%$ o más de los alimentos se consumen crudos (Koebnick et al. 2005). Una dieta de alimentos crudos puede tomar muchas formas. Si bien muchas dietas de alimentos crudos son veganas, lo que significa que no contienen alimentos de origen animal, algunas son vegetarianas y permiten lácteos y / o huevos, y otras son omnívoras y permiten carne, pescado y aves crudas. Sin embargo, lo que las dietas de alimentos crudos tienen en común es que excluyen todos los alimentos que se han cocinado, pasteurizado o calentado a más de $118^{\circ} \mathrm{F}$ $\left(48^{\circ} \mathrm{C}\right)$ (Cunningham 2004). En cambio, se consumen frutas crudas, verduras, semillas, nueces y granos y frijoles germinados. El aceite de oliva extra-virgen prensado en frío y el aceite de coco virgen crudo proporcionan fuentes de grasa. Algunas personas que siguen esta dieta pueden consumir leche no pasteurizada y pescado crudo, huevos y carnes. Los métodos de preparación de alimentos incluyen exprimir, deshidratar a baja temperatura y germinar.
Algunos métodos de preparación pueden requerir mucho tiempo y equipos costosos (por ejemplo, exprimidor de presión en frío, licuadora de gran volumen, procesador de alimentos y deshidratador).

\section{¿Qué dicen los defensores sobre los beneficios para la salud de la dieta de alimentos crudos?}

Los defensores de las dietas de alimentos crudos afirman que los alimentos crudos están llenos de enzimas naturales y nutrientes necesarios para la salud, y que cocinar los alimentos destruirá estas enzimas y nutrientes (Cunningham 2004). Sin embargo, es posible que algunos no se den cuenta de que tenemos una gran cantidad de enzimas digestivas humanas para digerir los carbohidratos, las proteínas y las grasas. Además, la microbiota intestinal proporciona una diversidad de enzimas adicionales y, por lo tanto, garantiza que la mayoría de los residuos de alimentos que escapan a la digestión se degraden en el intestino, lo que produce sustancias que mejoran la salud y proporcionan energía. Las enzimas de origen vegetal simplemente no son necesarias para la digestión y la salud humana. Aunque hay cierta pérdida de vitaminas cuando los alimentos se exponen a temperaturas más altas, la cocción en realidad mejora la digestibilidad de muchos alimentos, así como la disponibilidad de nutrientes (Carmody and Wrangham 2009).

1. Este documento, FSHN20-45s, es uno de una serie de publicaciones del Food Science and Human Nutrition, Servicio de Extensión Cooperativa de la Florida, Instituto de Alimentos y Ciencias Agrícolas, Universidad de la Florida. (UF/IFAS). Fecha de primera publicación: octubre 2020. Visite nuestro sitio web EDIS en https://edis.ifas.ufl.edu.

2. Alexa Barad, former MS-DI student; Daniela Rivero-Mendoza, Extension and research coordinator; and Wendy Dahl, associate professor, Food Science and Human Nutrition Department, UF/IFAS Extension; Gainesville, FL 32611.

The Institute of Food and Agricultural Sciences (IFAS) is an Equal Opportunity Institution authorized to provide research, educational information and other services

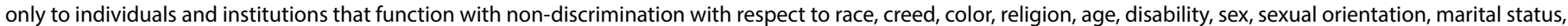

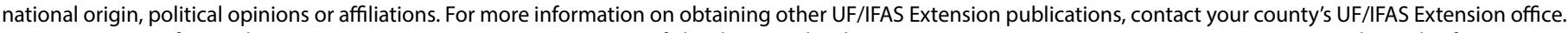
U.S. Department of Agriculture, UF/IFAS Extension Service, University of Florida, IFAS, Florida A \& M University Cooperative Extension Program, and Boards of County Commissioners Cooperating. Nick T. Place, dean for UF/IFAS Extension. 


\section{¿Cuáles son los posibles beneficios para la salud de una dieta de alimentos crudos?}

Se ha promocionado que la dieta de alimentos crudos mejora la salud y previene el desarrollo de enfermedades crónicas, pero hay poca o ninguna investigación que respalde estas afirmaciones. Sin embargo, es posible perder peso. Esto puede deberse en parte a la eliminación de alimentos procesados, densos en energía, con azúcares y grasas añadidos. La pérdida de peso también puede deberse a la malabsorción de almidón y proteínas. Por ejemplo, el almidón de los tubérculos crudos, como las patatas, es resistente a las enzimas digestivas a menos que se cocine. La cocción funciona para dispersar el almidón, lo que permite que las enzimas accedan al almidón para la digestión y, por lo tanto, aumenta la energía proporcionada por los alimentos (Carmody and Wrangham 2009). El calentamiento también altera la estructura de las proteínas, aumentando su digestibilidad al hacerlas más accesibles a las enzimas humanas (Carmody and Wrangham 2009). Cuando los alimentos se comen crudos, es posible que una cantidad significativa de almidón y parte de la proteína no se digieran y, en cambio, estos macronutrientes transiten por el intestino hasta el colon, donde son fermentados por las bacterias intestinales. La fermentación proporciona algo de energía, pero menos calorías que la digestión. Esta menor provisión de energía puede conducir a la pérdida de peso y la adherencia a largo plazo a una dieta de alimentos crudos puede conducir a un peso corporal por debajo de un rango saludable (Koebnick et al. 1999).

Por lo general, una dieta de alimentos crudos tiene un alto contenido de frutas y vegetales y, por lo tanto, un alto contenido de fibra, potasio y ciertas vitaminas. Las Guías Alimentarias para los estadounidenses promueven la ingesta de una variedad de frutas y vegetales, incluidas sus formas crudas (USDA 2015). No es sorprendente que los adultos que consumen una dieta de alimentos crudos, a largo plazo, tengan altas concentraciones plasmáticas de $\beta$-caroteno (Garcia et al. 2008), ya que el $\beta$-caroteno es abundante en las zanahorias, las batatas (patata dulce o camote) y otros vegetales y frutas. En un estudio de individuos que seguían una dieta rica en vegetales y frutas crudas (1500-1800 g / día), se reportaron concentraciones más bajas de colesterol LDL (malo) y triglicéridos (Koebnick et al. 2005), que, en general, se asocia con un riesgo reducido de enfermedades cardiovasculares (Grundy et al. 2019). Sin embargo, también se informó que el colesterol HDL (bueno) estaba más bajo (Koebnick et al. 2005). Es importante recordar que los beneficios de una alta ingesta de frutas y verduras se pueden obtener siguiendo patrones de alimentación menos restrictivos que una dieta de alimentos crudos.

\section{¿Cuáles son los riesgos de una dieta de alimentos crudos?}

La elección de consumir una dieta de alimentos crudos presenta riesgos para la salud. Los alimentos crudos pueden contener bacterias dañinas que pueden causar enfermedades graves y potencialmente mortales transmitidas por los alimentos. Los alimentos crudos de origen animal, específicamente la carne cruda, aves, huevos, mariscos y leche no pasteurizada, son los que tienen más probabilidades de estar contaminados por microorganismos dañinos (CDC 2020). Sin embargo, las frutas y verduras también pueden albergar microorganismos patógenos. Cocinar alimentos puede matar patógenos y ayudar a prevenir enfermedades transmitidas por los alimentos. Las aves y las carnes deben cocinarse a una temperatura interna segura $\left(145^{\circ} \mathrm{F}-165^{\circ} \mathrm{F}\left[63^{\circ} \mathrm{C}-74^{\circ} \mathrm{C}\right]\right.$, que requeriría una temperatura del horno de $325^{\circ} \mathrm{F}-450^{\circ} \mathrm{F}\left[163^{\circ} \mathrm{C}-232^{\circ} \mathrm{C}\right]$ ) para matar las bacterias dañinas (CDC 2020). Los huevos deben cocinarse hasta que las yemas y las claras estén firmes (CDC 2020). No se recomienda la leche no pasteurizada debido al alto riesgo de contaminación por microorganismos causantes de enfermedades (CDC 2020). Además, la germinación requiere condiciones cálidas y húmedas, ideales para el crecimiento de bacterias. Comer brotes crudos o ligeramente cocidos puede provocar enfermedades transmitidas por los alimentos (CDC 2020). Los Centros para el Control y la Prevención de Enfermedades (CDC) recomiendan cocinar los brotes a fondo para matar los microorganismos que causan enfermedades (CDC 2020). Las poblaciones que tienen un mayor riesgo de contraer enfermedades transmitidas por los alimentos son los niños, las mujeres embarazadas, los adultos mayores y cualquier persona con un sistema inmunológico comprometido. Para obtener más información sobre seguridad alimentaria, visite: https:// www.cdc.gov/foodsafety/index.html.

Además, algunos alimentos crudos contienen altas cantidades de compuestos llamados "anti nutrientes". Los anti nutrientes interfieren con la digestión y absorción de ciertos nutrientes, lo que puede resultar en deficiencias (Samtiya, Aluko, and Dhewa 2020). Por ejemplo, las legumbres crudas contienen altos niveles de anti nutrientes como lectinas, taninos, fenólicos, fitatos, saponinas e inhibidores de enzimas digestivas. Algunos métodos comunes para reducir los anti nutrientes en los alimentos incluyen remojar, cocinar, hervir, fermentar y germinar (Samtiya, 
Aluko, and Dhewa 2020; Patterson, Curran, and Der 2017). Al usar métodos combinados, como germinar y hervir, las personas pueden reducir los anti nutrientes y al mismo tiempo prevenir las enfermedades transmitidas por los alimentos.

\section{Resumen}

Las dietas de alimentos crudos son restrictivas y, por lo tanto, pueden ser difíciles de seguir a largo plazo. En general, los riesgos de seguir una dieta de alimentos crudos superan los posibles beneficios. Más importante aún, seguir esta dieta puede ponerlo en riesgo de enfermedades transmitidas por los alimentos y pérdida de peso no deseada. Se recomienda que las personas que actualmente sigan o estén considerando seguir una dieta de alimentos crudos, consulten a su proveedor de atención médica.

\section{Referencias}

Carmody, R., and R. Wrangham. 2009. "Cooking and the Human Commitment to a High-Quality Diet." Cold Spring Harbor Symposia on Quantitative Biology. 74:427-34. https://doi.org/10.1101/sqb.2009.74.019.

Centers for Disease Control and Prevention (CDC). 2020. "Foods That Can Cause Food Poisoning." https://www.cdc. gov/foodsafety/foods-linked-illness.html [Accessed 24th July 2020].

Cunningham, E. 2004. "What Is a Raw Foods Diet and Are There Any Risks or Benefits Associated with It?" Journal of the American Dietetic Association 104 (10): 1623. https:// doi.org/10.1016/j.jada.2004.08.016h.

Garcia, A. L., C. Koebnick, P. C. Dagnelie, C. Strassner, I. Elmadfa, N. Katz et al. 2008. "Long-Term Strict Raw Food Diet Is Associated with Favourable Plasma $\beta$-carotene and Low Plasma Lycopene Concentrations in Germans." British Journal of Nutrition. 99 (6): 293-300. https://doi. org/10.1017/S0007114507868486.

Grundy, S. M., N. J. Stone, A. L. Bailey, C. Beam, K. K. Birtcher, R. S. Blumenthal et al. 2019. "2018 AHA/ACC/ AACVPR/AAPA/ABC/ACPM/ADA/AGS/APhA/ASPC/ NLA/PCNA Guideline on the Management of Blood Cholesterol: A Report of the American College of Cardiology/American Heart Association Task Force on Clinical Practice Guidelines." Circulation. 139 (25): e1082-e143. https://doi.org/10.1161/CIR.0000000000000625.
Koebnick, C., A. Garcia, P. Dagnelie, C. Strassner, J. Lindemans, N. Katz et al. 2005. "Long-Term Consumption of a Raw Food Diet Is Associated with Favorable Serum LDL Cholesterol and Triglycerides but Also with Elevated Plasma Homocysteine and Low Serum HDL Cholesterol in Humans." The Journal of Nutrition 135 (10): 2372-8. https:// doi.org/10.1093/jn/135.10.2372.

Koebnick, C., C. Strassner, I. Hoffmann, and C. Leitzmann. 1999. "Consequences of a Long-Term Raw Food Diet on Body Weight and Menstruation: Results of a Questionnaire Survey." Annals of Nutrition and Metabolism. 43 (2): 69-79. https://doi.org/10.1159/000012770.

Leitzmann, C. 2014. "Vegetarian Nutrition: Past, Present, Future." The American Journal of Clinical Nutrition 100 (1): 496S-502S. https://doi.org/10.3945/ajcn.113.071365.

Patterson, C., J. Curran, and T. Der. 2017. "Effect of Processing on Antinutrient Compounds in Pulses." Cereal Chemistry 94 (1): 2-10. https://doi.org/10.1094/ CCHEM-05-16-0144-FI.

Samtiya, M., R. Aluko, and T. Dhewa. 2020. "Plant Food Anti-nutritional Factors and Their Reduction Strategies: An Overview." Food Production, Processing and Nutrition 2:6. https://doi.org/10.1186/s43014-020-0020-5.

United States Department of Agriculture (USDA). 2015. Dietary Guidelines for Americans 2015-2020. https:// health.gov/our-work/food-nutrition/2015-2020-dietaryguidelines/guidelines/ [Accessed 24th July 2020]. 